\title{
Cocaine induced myocardial infarction
}

\author{
V A Inyang, A J Cooper, D W Hodgkinson
}

\begin{abstract}
The case of a 29 year old man who presented with chest pains after the use of cocaine is reported. The diagnosis of myocardial infarction was made on the electrocardiogram changes and lactate dehydrogenase profile. The diagnosis may be overlooked if there is no direct questioning about the use of drugs such as cocaine.

Diazepam has an important role in the management of cardiac complications after cocaine use and should be used early in management. The use of thrombolysis should be a joint decision between the emergency physician and cardiologist. ( $F$ Accid Emerg Med 1999;16:374-375)
\end{abstract}

Keywords: cocaine; myocardial infarction

\section{Case report}

A 29 year old man attended the accident and emergency department with a three hour history of central chest pain. The pain was described as severe, had no radiation, and was not affected by posture or respiratory effort. The patient denied any flu-like symptoms in the preceding two weeks. There was no significant past history of respiratory or cardiovascular disease. The patient smoked 5-10 cigarettes per day but had no other cardiac risk factors. There was no family history of premature death from cardiovascular disease.

Examination revealed a young man in pain. The pulse was 100 beats $/ \mathrm{min}$ with a blood pressure of $170 / 110 \mathrm{~mm} \mathrm{Hg}$. An electrocardiogram (ECG) performed at 20:00 hours showed

Department of

Accident and

Emergency Medicine, Ipswich Hospital NHS Trust, Ipswich

V A Inyang

D W Hodgkinson

Department of Accident and Emergency Medicine, Addenbrooke's Hospital NHS Trust, Cambridge

A J Cooper

Correspondence to: Mr Victor Inyang, Specialist Registrar, Accident and Emergency Department, Addenbrooke's Hospital, Cambridge CB2 2QQ.

Accepted 11 February 1999 ST segment elevation in lead V1 with ST depression in lead III. Leads V3/4 exhibited a high take-off pattern.

In view of the patient's history and the ECG changes he was asked directly about the use of drugs. With great reluctance he admitted to "snorting" a line of cocaine 30 minutes before the pain began. A working diagnosis of myocardial ischaemia secondary to coronary artery vasospasm was made and treatment was started with supplementary oxygen, sublingual nitrate, and intravenous diamorphine.

At this stage the patient was transferred to the coronary care unit. In spite of intravenous opiates and buccal nitrates the chest pain persisted. In view of this a glyceryl trinitrate infusion was started at 21:15 hours with the rate titrated to pain and blood pressure. By 21:40 hours the chest pain was still present and severe leading to the addition of a labetalol infusion to provide a theoretical $\alpha$ and $\beta$ blockade effect. We later discovered this to be a therapeutical error.

An ECG performed at 23:20 hours showed extension of the ST elevation towards V4, indicating an increasing area of myocardial ischaemia/infarction. The patient was still experiencing central chest pain at this stage. Creatinine kinase MB fraction was less than $2 \mathrm{U} / 1$ with a lactate dehydrogenase level of $481 \mathrm{U} / 1$. An echocardiogram was not performed acutely.

At this point the initial diagnosis was revised to myocardial infarction and thrombolysis was started with recombinant tissue plasminogen activator and heparin. The patient did not experience any complications during thrombolysis. An echocardiogram performed after thrombolysis revealed slightly reduced septal wall movement.

The patient was discharged on the seventh day with plans for an exercise stress test in six weeks. Unfortunately he was lost to follow up.

\section{Discussion}

Myocardial infarction after cocaine use was first reported in 1982. Since then over 250 cases have been reported, mostly in the United States. We are not aware of any reports from the UK.

A total of $940.7 \mathrm{~kg}$ of cocaine with a street value of $£ 109.5$ million pounds was seized by Her Majesty's Customs in 1995. Correcting for three large seizures in 1994 this represents an increase of $125 \%$ on 1994 figures (personal communication, Press and PR Office, HM Customs and Excise).

We believe these figures put into perspective the potential problems emergency physicians may face in the future. This case highlighted certain areas of difficulty that will be faced by any emergency physician who has to deal with a similar patient, namely:

- Making a precise diagnosis with a limited history.

- The issue of $\alpha / \beta$ blockade in cocaine induced myocardial ischaemia.

- The decision to thrombolyse such a patient. Obtaining the correct history is dependent on maintaining a high index of suspicion and direct questioning is required to make the diagnosis. Other drugs that may cause myocardial ischaemia that we need to inquire about are:

- Amphetamines and their derivatives, which are contained in drugs such as "speed".

- Caffeine taken as an overdose. 
- Volatile hydrocarbon solvents such as toluene. These may be found in lighter fluid, which can be abused by younger patients $(<18$ years).

- Anabolic steroids. ${ }^{1-4}$

Myocardial ischaemia due to cocaine can be explained by at least three mechanisms:

(1) The effect on blood constituents by increasing thrombogenicity, enhancing platelet aggregation through adenosine diphosphate, and decreasing fibrinolysis by increasing the concentrations of endogenous inhibitors of tissue plasminogen activator. ${ }^{5}$

(2) The sympathomimetic effect causes tachycardia and hypertension. At the same time $\alpha$ mediated vasoconstriction of the coronary artery reduces coronary artery blood flow.

(3) The effect on coronary vessel damage. With chronic use, left ventricular hypertrophy and premature artherosclerosis may develop. ${ }^{6}$ This feature needs to considered when arranging post-myocardial infarction risk stratification. Chronic abuse is associated with two or three vessel disease and these patients may require coronary angiography to define the extent of coronary vessel damage.

The current recommended management of cocaine induced myocardial ischaemia/ infarction is based on the experience of emergency physicians in the United States, evidence derived from a review of current medical literature, and an understanding of the pathophysiological process.

Management may be divided into two phases. Second phase management should be considered in patients with continuing chest pain or evolving ECG changes.

PHASE 1

- Oxygen treatment: usually delivered via a facemask at $10 \mathrm{l} / \mathrm{min}$.

- Diazepam: this reduces central nervous stimulation and decreases sympathetic outflow.

Reduction in hypertension and tachycardia will decrease myocardial oxygen demand. Diazepam alone will often return vital signs to normal. This is a relatively new role for diazepam and the current evidence supports this. ${ }^{7}$

- Aspirin: this may be used to decrease hypercoagulability. The normal myocardial infarction dose of $300 \mathrm{mg}$ should achieve this effect, although a logical intervention research regarding the use of aspirin in this specific condition does not exist.

- Nitroglycerin: this relieves chest pain in cocaine induced coronary artery spasm. The sublingual route appears to relieve chest pain most rapidly. ${ }^{8}$

If the intravenous route is chosen the infusion rate is titrated to pain and the systolic blood pressure.

PHASE 2

- The use of labetalol is inadvisable. The $\alpha$ adrenergic response is enhanced worsening vasospasm. We should not have used it in this patient and its use may in part explain the difficulty in relieving our patient's pain. Phentolamine blocks the $\alpha$ receptors and may be useful. After the administration of a benzodiazepine it may precipitate hypotension. Low doses (1 $\mathrm{mg}$ given in intravenous boluses) are safe. ${ }^{9}$

The use of $\beta$ blockers in the early management of acute myocardial infarctions has been shown to decrease mortality due to ventricular wall rupture. In cocaine induced myocardial infarction the use of $\beta$ blockers will result in unopposed $\alpha$ receptor stimulation. This will result in an exacerbation of coronary vasoconstriction with an increase of the area of myocardial ischaemia/infarction. We would not advocate its use during the emergency department phase of the management of this condition.

- Thrombolysis may be considered in a small number of patients with cocaine induced myocardial infarction. The poor diagnostic specificity (35\%) of ECGs and the low mortality of this condition ( $0-4 \%)$ are arguments against the use of thrombolysis. ${ }^{7}$

A retrospective cross sectional survey on the safety of thrombolysis in cocaine associated myocardial infarction was undertaken by the Cocaine Associated Myocardial Infarction (CAMI) group; 66 cases were reviewed. Twenty five received thrombolysis while 41 who met electrocardiographic Thrombolysis In Myocardial Infarction (TIMI) criteria did not receive thrombolysis. There were no major complications or deaths in the group that received thrombolysis. ${ }^{10}$

Thrombolysis may be considered in patients who:

- Have an extension of ST segment elevation. - Have echocardiographic wall motion abnormalities. ${ }^{7}$

Emergency echocardiograhphy is not readily available in most centres in the UK and the decision will have to be based on the patient's symptoms, evolution of the ECG, and the advice of a cardiologist.

The role of thrombolytic treatment in cocaine associated myocardial infarction is still unclear and larger studies are awaited that may clarify this position.

Conflict of interest: none.

Funding: none.

1 Hussain TF, Heidenreich PA, Benowitz N. Recurrent non-Q-wave myocardial infarction associated with toluene non-Q-wave myocardial infarction as

2 Derreza H, Fine MD, Sadaniantz A. Acute myocardial Derreza $\mathrm{H}$, Fine $\mathrm{MD}$, Sadaniantz A. Acute myocardial
infarction after use of pseudoephedrine for sinus congesinfarction after use of pseudoephedrine for
tion. $\mathcal{F}$ Am Board Fam Pract 1997;10:436-8.

3 Forman J, Aizer A, Young CR. Myocardial infarction resultForman J, Aizer A, Young CR. Myocardial infarction result-
ing from caffeine overdose in an anorectic woman. $A n n$ Emerg Med 1997;29:178-80.

4 Fisher M, Appleby M, Rittoo D, et al. Myocardial infarction with extensive intracoronary thrombus induced by anabolic steroids. Br f Clin Pract 1996;50:222-3.

5 Moliterno DJ, Lange RA, Gerard RD, et al. Influence of intranasal cocaine on plasma constituents associated with endogenous thrombosis and thrombolysis. $\mathrm{Am} \mathcal{F} \mathrm{Med}$ 1994;96:492-6.

6 Eichorn EJ, Paecock E, Grayburn PA, et al. Chronic cocaine abuse in association with accelerated atherosclerosis in human coronary arteries. F Am Coll Cardiol 1992;19:105A

7 Spivey WH, Schoffstall JM, Kirkpatrick R, et al. Comparison of labetalol, diazepam, and haloperidol for the treatment of cocaine toxicity in a swine model. Ann Emerg Med 1990;19:467-8.

8 Brogan WC, Lange RA, Kim AS, et al. Alleviation of cocaine-induced coronary vasoconstriction by nitroglycerin. $\mathcal{F}$ Am Coll Cardiol 1991;19:581-6.

9 Hollander JE. Cocaine associated myocardial infarction. $f R$ Soc Med 1996;89:443-7.

10 Hollander JE, Burstein JL, Hoffman RS, et al. Cocaineassociated myocardial infarction. Clinical safety of thrombolytic therapy. Cocaine Associated Myocardial Infarction bolytic therapy. Cocaine Associated Myocardial Int
(CAMI) Study Group. Chest 1995;107:1237-41. 